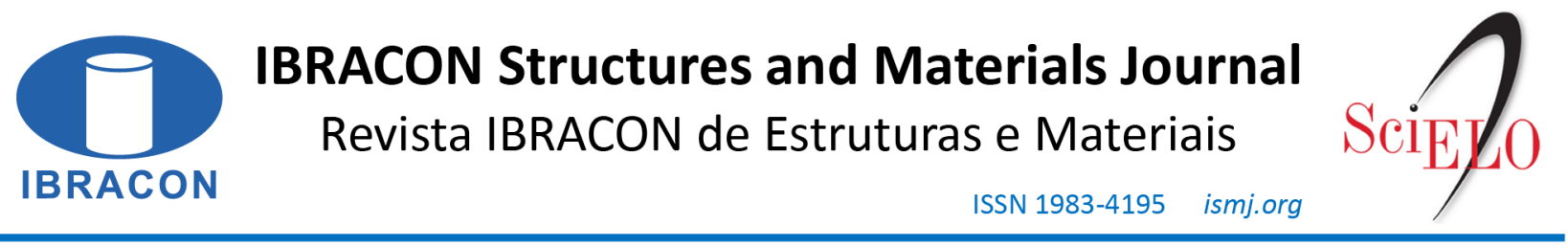

ORIGINAL ARTICLE

\title{
Study of the influence of the foundation and the reservoir on the dynamic response in a concrete gravity dam profile
}

\section{Estudo da influência da fundação e do reservatório na resposta dinâmica de um perfil de barragem gravidade}

Iarly Vanderlei da Silveira ${ }^{\mathrm{a}}$ (iD)

Lineu José Pedroso ${ }^{\mathrm{b}}$ (1)

Giuliano Santa Marotta ${ }^{\mathrm{c}}$

${ }^{a}$ Instituto Federal da Paraíba, Departamento de Engenharia Civil, Cajazeiras, PB, Brasil

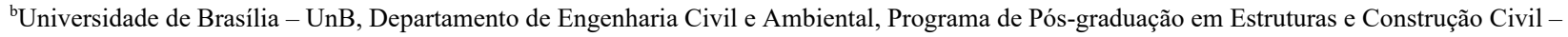
PECC, Grupo de Dinâmica e fluido-Estrutura - GDFE, Brasília, DF, Brasil

'Universidade de Brasília - UnB, Instituto de Geociências, Programa de Pós-graduação em Geociências Aplicadas e Geodinâmica, Brasília, DF, Brasil

Received 13 October 2020

Accepted 04 January 2021

\begin{abstract}
This work aims to verify the influence of the foundation and the reservoir on the dynamic behavior of concrete gravity dams in terms of the natural frequencies, vibration modes for a free vibration analysis; and in terms of maximum displacements and maximum stresses at singular points of the structure for a seismic excitation. The dam-reservoir-foundation interaction was investigated through modal and transient analysis by the finite element method via ANSYS APDL software. For this study, we used a typical Brazilian dam profile and compatible data from a Brazilian earthquake for the seismic excitation. The results showed the influence of the reservoir and the foundation on the natural frequencies in the coupled system, as well as its repercussions on the response of the dam under seismic excitation.
\end{abstract}

Keywords: dam-reservoir-foundation interaction, dynamic analysis, foundation flexibility, reservoir, ANSYS.

\begin{abstract}
Resumo: Este trabalho tem o objetivo de verificar a influência da fundação e do reservatório no comportamento dinâmico em barragens gravidade de concreto, avaliando as frequências naturais e os modos de vibração para uma análise em vibração livre; assim como os deslocamentos máximos e as tensões máximas em pontos singulares da estrutura para uma excitação sísmica. A interação barragem-reservatório-fundação é investigada através da análise modal e transiente pelo método dos elementos finitos via software ANSYS APDL. Adotou-se um perfil de barragem típica brasileira e dados compatíveis de um sismo local para a excitação sísmica. Para o caso de vibração livre, os resultados mostraram a influência do reservatório e da fundação nas frequências naturais no sistema acoplado e a sua correlação com os resultados obtidos para o sistema desacoplado, já para a excitação sísmica houve modificações na resposta da estrutura com a alteração, em especial, do tipo de fundação.
\end{abstract}

Palavras-chave: interação barragem-reservatório-fundação, análise dinâmica, fundação flexível, reservatório, ANSYS.

How to cite: I. V. Silveira, L. J. Pedroso, and G. S. Marotta, "Study of the influence of the foundation and the reservoir on the dynamic response in a concrete gravity dam profile," Rev. IBRACON Estrut. Mater., vol. 14, no. 4, e14403, 2021, https://doi.org/10.1590/S1983-41952021000400003

\section{INTRODUCTION}

The knowledge of the behavior of concrete gravity dams under dynamic load is an important issue in the evaluation of these structures stability. The assessment of the actual behavior of dams under dynamic loads is complex because it 
deals with a massive structure that presents non-linear characteristics and because it involves the interaction of three elements: the water of the reservoir, the soil of the foundation and the concrete of the dam.

Some studies in this field consider only the interaction between the fluid and the structure as preponderant in the dynamic assessment. However, recent research also shows the influence of the foundation [1], [2]. The study of soilstructure interaction (SSI) and fluid-structure interaction (FSI) in dams has advanced well over the last few years, in spite of requiring more refined investigations and more sophisticated models.

The SSI is an important factor to be considered and it requires special attention in dam constructions. It is also necessary to know the deformability of the foundations, the ration between the applied load and the resultant deformations, due to the potential differential settlements in the foundation.

The effects of the FSI are important in the coupled dam reservoir problems under seismic loads or in the case of fluid induced vibrations. The movement of the structure inevitably causes a movement of the fluid in contact with the structure walls. As a result, the fluid-structure assembly constitutes a coupled system for which it is often impossible to consider the responses and excitations separately.

Because the coupled system involves elements of different physical properties and requires a complex approach, an analytical treatment is often limited depending on the problem requirements. Thus, the finite element method (FEM) fits well in solving these problems due to its ability to discretize irregular geometries and solve cases involving the structure, the foundation and the reservoir fluid interacting with each other.

The methods used for the dynamic analysis of dam-gravity of concrete-reservoir were first developed by Westergaard [3], who obtained analytically, by using solution of the Laplace equation, the distribution of pressures along the fluid-structure interface.

Westergaard assumed that the hydrodynamic effect on a rigid dam during an acceleration is equivalent to an inertial force resultant from a mass distribution added to the dam body (additional mass), a method named pseudo static. Chopra [4] observed that the response of a dam when subjected to seismic loads was largely influenced by the fundamental mode of vibration, i.e., both the inertial and hydrodynamic forces depended on the fundamental mode of the structure vibration. Subsequently, Chopra and Chakrabarti [5], Hall and Chopra [6], Fenves and Chopra [7], Chopra and Zhang [8] and Ribeiro and Pedroso [9] evaluated other aspects that influenced the dam response under dynamic excitation, namely: fluid compressibility, fundamental vibration mode, foundation flexibility, as well as vertical and horizontal components of the earthquake. With the advancement of these studies and from the understanding of the problems involved, the researchers began to evaluate more complex geometries and problems, which mainly comprised the dam - reservoir foundation coupled system. The pioneering SSI studies, Novak [10] and, Léger and Katsouli [11], evaluated the stability of the dam to landslide and tipping in a seismic analysis influenced by the variation of the foundation properties. In addition, Bougacha et al. [12] analyzed the effect of the sediments in the dam-reservoir-sediment-foundation interaction in the harmonic movements of the dam. In a more recent studies, Ghannat [13] highlighted factors that can affect dam stability and its foundation, such as overload, joint opening and failure modes. Inaudi et al. [14] evaluated the simplified linear methods for preliminary seismic analysis of dams, in particular, the influence of the foundation flexibility on the response. Lin et al. [15] analyzed the influence of the heterogeneity of the foundation that may cause an increase in the response of the dam; and Papazafeiropoulos et al. [16] presented a formulation based on finite elements for complex reservoir, foundation and dam geometries, evaluating the interaction of those elements and the influence of their characteristics, such as the thickness of the soil layer, the flexibility of the foundation and the presence of sediments. Burman et al. [17] showed in their study a free-field formulation used in dynamic analyzes involving SEI. Chopra [18] indicates that the flexibility of the foundation causes large displacements in the crest when studying the dam of Pine Flat submitted to a local earthquake. This author, in recent studies, has investigated the absorbent boundary conditions through damping elements for the foundation and the reservoir. Lokke and Chopra [1] it is presents a generalization for the conditions of non-return of the wave in the contour of a 3D arc dams involving a seismic excitation. A numerical formulation integrating dam-reservoir-foundation involving the three interacting media, which is based on the finite difference method (FDM) in a physical-intuitive manner, allowing the assemblage a complete matrix system to be solved, is presented in Pedroso [19].

This paper presents a discussion on the main aspects of a dynamic assessment in a concrete gravity dam, with typical dimensions in Brazil, which involves the study of free vibration and seismic excitation influenced by the foundation and the reservoir. Variables considered in the analyses include the variation of the modulus of elasticity of the foundation, and the influence in the reservoir of the distant boundary condition, evaluating the case of zero pressure and the case of the non-return condition of the wave (Sommerfield condition). 
Simulations were run with the ANSYS program. An actual record of soil movements in Brazil, obtained through the partnership with the Seismological Observatory (OBSIS) of the University of Brasília (UnB), was considered in the analyses. It must be pointed out that few studies reproduce a real record on Brazilian soil.

\section{PROBLEM DESCRIPTION}

The dam-reservoir-foundation system consists of three sub-systems: the concrete dam; the rock of the foundation consisting as the structure support region, and the fluid domain having a border region with arbitrary geometry adjacent to the dam consisting of a uniform and infinite channel in the upstream direction.

For a dynamic analysis of gravity dams, these sub-systems are interacting with each other and may involve numerous variables such as local geological faults, seismic motions with wave propagation in all directions on the ground, non-linearities of materials and infinite contours in the soil and reservoir. Thus, the analyses of these structures can be extremely complex. In order to simplify, a 3D analysis can be seen in Figure 1a. By involving these problems, it is used, initially, the hypothesis that the structure can be represented by an $2 \mathrm{D}$ slice. (Figure 1b), in which the dam body behaves in the plane state of deformation, where the solicitations are, essentially within the $\mathrm{x}-\mathrm{z}$ plane. Thus, the region of analysis of the dam-reservoir-foundation system is limited to a zone of finite domain for the problem, considering the entire linear, isotropic and homogeneous system. Figure 1b illustrates the simplified 2D system.

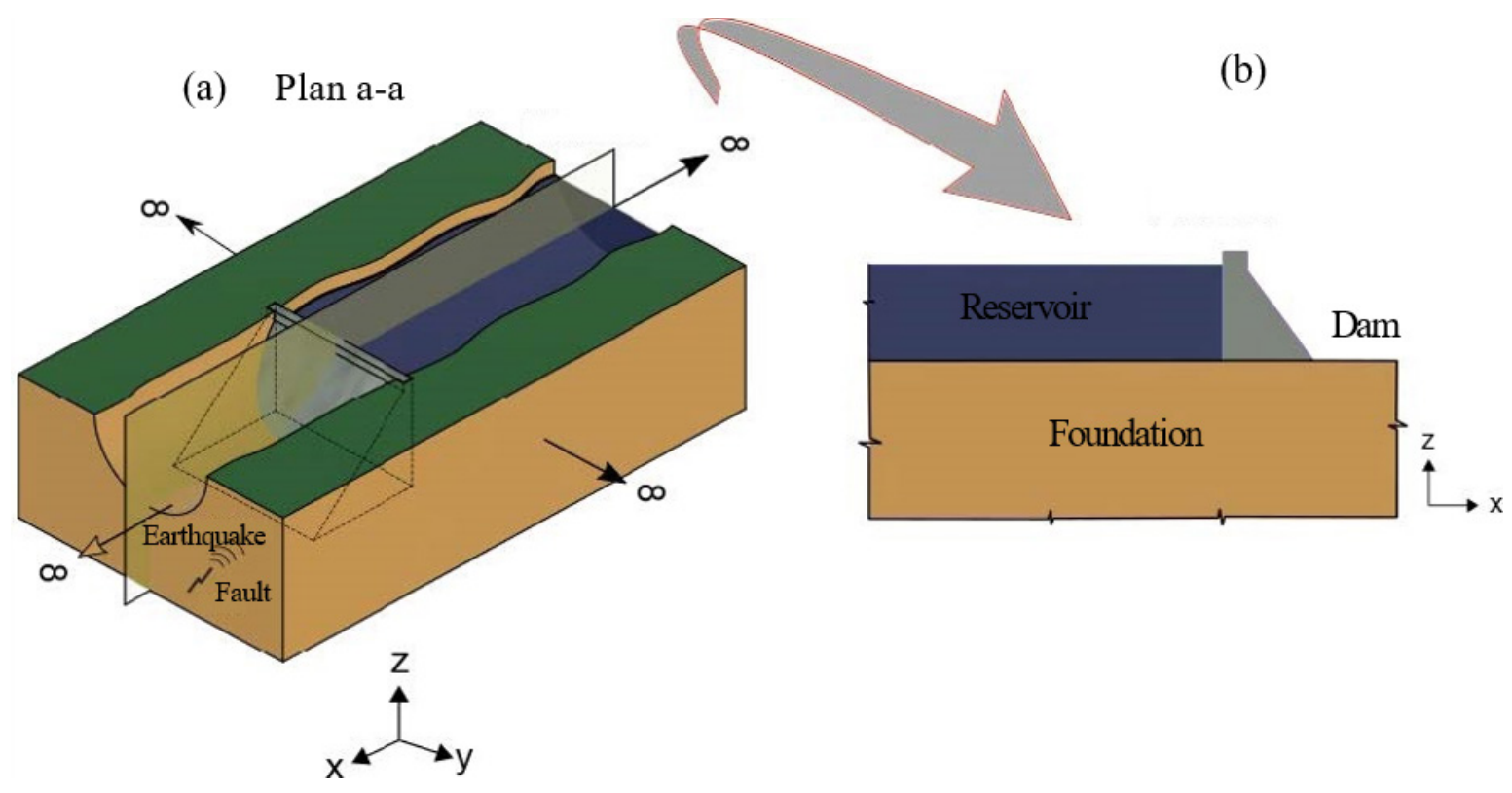

Figure 1. Dam gravity-reservoir-foundation coupled system: (a) 3D and (b) 2D.

\section{THEORETICAL FORMULATION AND NUMERICAL MODEL}

For the modeling of the coupled gravity-reservoir-foundation dam system involving, respectively, the interaction between concrete, water and soil in dynamic problems, a finite element formulation was used to discretize the equations of each means. Assuming some simplifications, namely:

- The dam structure and the foundation material are composed of linear, elastic and isotropic materials;

- The foundation is considered massless, to avoid the propagation and reflection problems of waves in the seismic analysis and;

- The fluid is considered quiescent (stagnant), inviscid (non-viscous) and incompressible. There is no flow, existing only vibration around a position of equilibrium (acoustic fluid).

The problem involving the dynamic effect between dam, reservoir and foundation must be studied together and integrated, since these means do not behave in isolation.

To include the effect of SSI, a formulation proposed by Burman et al. [17] was used, which the relates of the overlap of effects in terms of free field displacements. 
In the formulation of the SSI dynamic equilibrium equations, the structure - foundation coupled system and interface zone are considered as shown in Figure 2, which shows the structure nodes, the foundation soil nodes and the common nodes at the soil-structure interface.

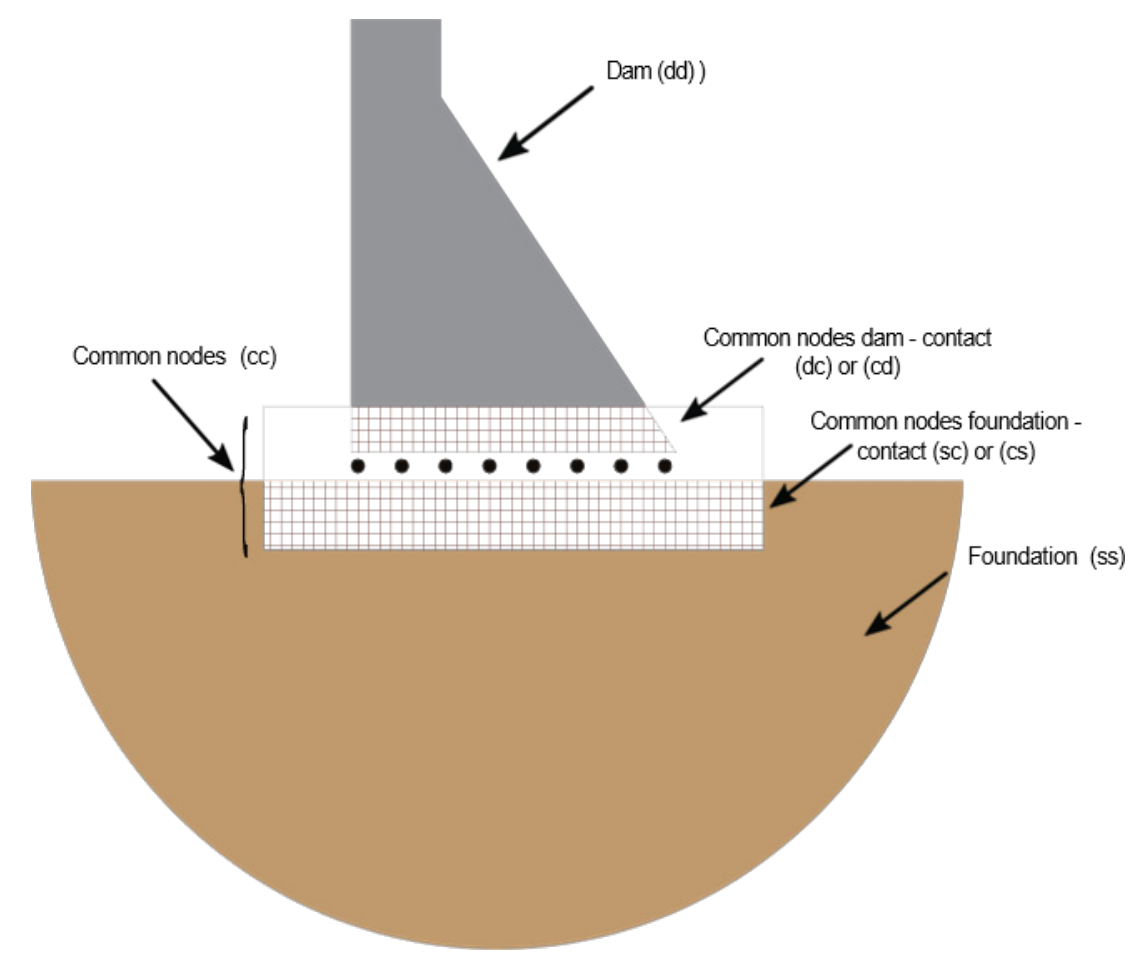

Figure 2. Interaction system foundation (s), dam (d) and the common interface zone (c).

The free field formulation leads to the following equation:

$$
\left[M_{b s}\right]\left\{\ddot{U}{ }_{b s}\right\}+\left[C_{b s}\right]\left\{\dot{U}_{b s}\right\}+\left[K_{b s}\right]\left\{U_{b s}\right\}=F=-\left[M_{b s}\right]\{\ddot{U} g\}
$$

in which the matrices $M_{b s}, C_{b s}, K_{b s}$ represent, respectively, the mass, damping and stiffness of the complete dam foundation system. The matrix $\ddot{U}_{g}$ represents the movement of the soil imposed by the seismic excitation, i.e., the vector F comprises the forces of seismic excitation acting at the base of the structure. The vector $U_{b s}$ consists in the displacements of the nodes in relation to the base and the time derivatives, while $\dot{U}_{b s}$ and $\dot{U}_{b s}$ are, respectively, the velocity and the acceleration on these nodes.

For the study of the FSI, without the influence of the foundation, a dam-reservoir coupling model was used, within the hypotheses of small displacements for the structure and the fluid. The domain of the fluid is ruled by the twodimensional wave equation:

$\nabla^{2} p-\frac{1}{c^{2}} p=0$

The term $\nabla^{2}$ corresponds to a stiffness operator, whereas $\frac{1}{c^{2}}$ is a mass operator, in which $\mathrm{c}$ is the velocity of the wave, $\mathrm{p}$ is the hydrodynamic acoustic pressure and $\mathrm{t}$ is the time. In order to solve the Equation 2, one must satisfy the 
boundary conditions that are shown in Figure 3. The boundaries of the reservoir comprise the interface with the dam $\left(\Gamma_{1}\right)$, the bottom $\left(\Gamma_{2}\right)$, the radiation at infinity $\left(\Gamma_{3}\right)$ and the free surface $\left(\Gamma_{4}\right)$.

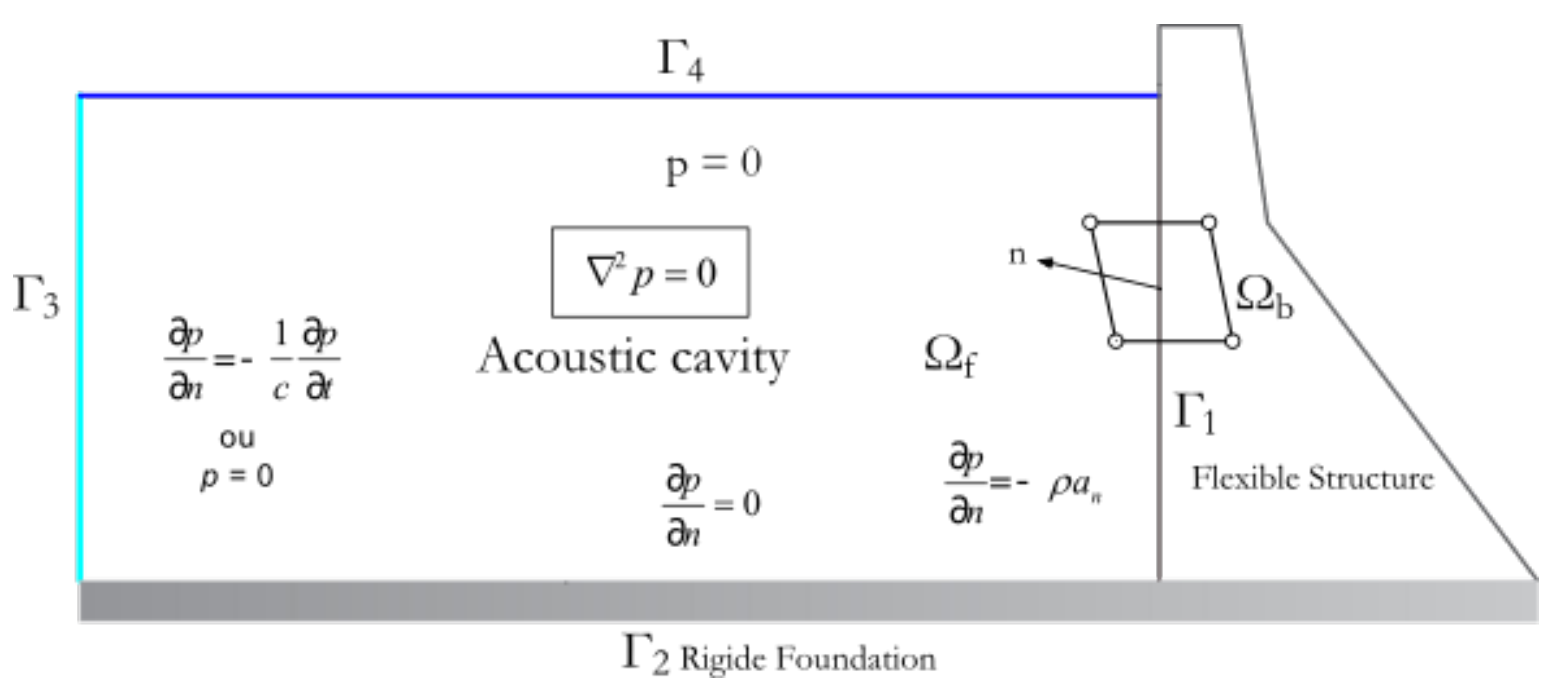

Figure 3. Fluid-structure interaction system.

The mathematical problem described by Equation 2, with the respective boundary conditions presented by the Figure 3 and discretization by the finite element method, leads to the equation of the movement of the reservoir (fluid) given by the matrix expression 3 .

$$
\left[M_{f}\right]\left\{\ddot{P} P_{f}\right\}+\left[C_{f}\right]\left\{\dot{P}_{f}\right\}+\left[K_{f}\right]\left\{P_{f}\right\}-\rho\left[Q^{T}\right]\left\{\ddot{U}_{b s}\right\}=[0]
$$

in which $M_{f}, C_{f}, K_{f}$, are respectively the mass matrices, damping and stiffness of the fluid, $P_{f}$ and their derivatives represent the pressure and their variations, respectively. The term represents $\rho\left[Q^{T}\right]$ the coupling between the fluid and the structure.

A more complete development on the problem of acoustic cavities and fluid-structure interaction is found in Pedroso [20], [21].

The dynamic equation of the structure coupled to the foundation can be written similarly to Equation 1 by adding the term that represents the force associated with the hydrodynamic pressure produced by the reservoir, that is:

$$
\left[M_{b s}\right]\{\dot{U} b s\}+\left[C_{b s}\right]\left\{\dot{U}_{b s}\right\}+\left[K_{b s}\right]\left\{U_{b s}\right\}=\left[M_{b s}\right]\{\ddot{U} g\}+[Q]\left\{P_{f}\right\}=[0]
$$
follows:

The global system soil-fluid-structure coupled is obtained by regrouping the two systems [1] and [4] into one as

$$
\left[\begin{array}{cc}
M_{b s} & 0 \\
\rho\left[Q^{T}\right] & M_{f}
\end{array}\right]\left\{\begin{array}{c}
\ddot{U_{b s}} \\
\ddot{P_{f}}
\end{array}\right\}+\left[\begin{array}{cc}
C_{b s} & 0 \\
0 & C_{f}
\end{array}\right]\left\{\begin{array}{c}
\dot{U}_{b s} \\
\dot{P}_{f}
\end{array}\right\}+\left[\begin{array}{cc}
K_{b s} & -Q \\
0 & K_{f}
\end{array}\right]\left\{\begin{array}{c}
U_{b s} \\
P_{f}
\end{array}\right\}=\left\{\begin{array}{c}
-M_{b s} \dot{U}_{g} \\
0
\end{array}\right\}
$$

The Equation 5 discretized by the MEF via ANSYS will be used for the analysis that will be object of our studies, involving the three media in question: 
i) Modal analysis - decoupled and coupled free vibrations;

ii) Transient analysis - seismic excitation decoupled and coupled, as can be observed in Table 1.

Table 1. Cases analyzed in this work and their main characteristics

\begin{tabular}{|c|c|c|c|c|}
\hline \multirow{2}{*}{$\begin{array}{c}\text { Cases (Dynamic } \\
\text { Analysis) }\end{array}$} & \multirow{2}{*}{ System } & \multirow{2}{*}{ Scheme } & Foundation rock & \multirow{2}{*}{ Reservoir boundary } \\
\hline & & & $\mathbf{E}_{\mathbf{f}} / \mathbf{E}_{\mathbf{c}}$ & \\
\hline \multirow{3}{*}{ Modal } & DF & & 1,2 e 5 & --- \\
\hline & $\mathrm{R}$ & & --- & Zero pressure \\
\hline & DRF & & 1,2 e 5 & Zero pressure \\
\hline \multirow{3}{*}{ Transient } & DF & & 1,2 e 5 & --- \\
\hline & DRF & & 5 & Zero pressure \\
\hline & DRF & & 1,2 e 5 & Sommerfield condition \\
\hline
\end{tabular}

\section{RESULTS AND DISCUSSIONS}

\subsection{Introduction}

To obtain the dynamic response, modal and transient analyses were performed. In the first analysis, the natural modal frequencies and mode shapes were determined, whereas in the second, the history of displacements and stresses under seismic load were obtained.

In the modeling of the structure, the following physical properties were adopted for the concrete of the dam: specific mass equal to $2500 \mathrm{~kg} / \mathrm{m}^{3}$, Young's modulus equal to $25 \mathrm{GPa}$, Poisson's coefficient equal to 0,25 . The physical properties of water are: velocity of sound $1440 \mathrm{~m} / \mathrm{s}$ and specific mass $1000 \mathrm{~kg} / \mathrm{m}^{3}$. The soil of the foundation is assumed to be massless, in order to avoid the problems associated with propagation and wave reflections.

For a parametric soil-structure variation, it was used the relation between the modulus of elasticity of the foundation and the concrete: $\frac{E_{f}}{E_{c}}=1,2$ and 5 . This variation can be found for different types of rock, from possible altered granites $\frac{E_{f}}{E_{c}}=1$, gneiss $\frac{E_{f}}{E_{c}}=2$ and shale $\frac{E_{f}}{E_{c}}=5$. It should be noted that the modulus of elasticity of the foundation together with the Poisson's ratio and resistance to simple compression determine the modulus of deformability of the foundation, an important parameter for dam projects.

In the seismic excitation, the Rayleigh damping was considered with a value of $5 \%$ for the damping factor of the dam and soil coupled system.

For the structure and foundation, it was used the finite element - Plane 183 (plane strain). In the interface of the soilstructure interaction problem, it was utilized the elements 172 and TARGE 169, which make the connection between the nodes and the elements on the contact surfaces. For the reservoir it was used the FLUID29 element. At the far end of the reservoir, it was used the FLUID 129 element that is responsible for the absorption of waves in the boundary (non-return wave - Sommerfield condition).

The case studies analyzed in this work are oriented to the analysis of a typical 2 D profile of Brazilian dams, in accordance with the conditions and physical constants prescribed in this section. 
Table 1 shows the simulation plan performed in this work for the different types of dynamic analysis (modal or transient) performed with the coupled and decoupled system. Also included in the simulations are the influence of the foundation: flexible $E_{f} / E_{c}=1$; intermediary $E_{f} / E_{c}=2$ and rigid $\left(E_{f} / E_{c}=5\right)$, as well as the boundary condition for the distant boundary of the reservoir (zero pressure and non-return condition of the wave or absorbent element Sommerfield condition).

The dimensions of the system are presented in Table 2 and modelling of finite element mesh is shown in Figure 4. The distant dimensions for the reservoir and foundation were based on literature studies Løkke e Chopra [1]; Silveira and Pedroso [22]; Zeidan [23]; Huang [24]; Nascimento [25] and Gutstein [26], that have analogous and/or equivalent relations to represent the dimensions of the domain under study.

Table 2. Dimensions of the typical profile of a Brazilian dam, reservoir and foundation

\begin{tabular}{cccccc}
\hline Parameter & $\mathbf{H}$ & $\mathbf{h}_{\mathbf{c}}$ & $\mathbf{h}_{\mathbf{g}}$ & $\mathbf{B}$ & $\mathbf{H r}$ \\
\hline Value $(\mathbf{m})$ & 80 & 20 & 15 & 70 & 72 \\
\hline
\end{tabular}

Therefore, the finite dimensions used to represent the model with ratios proportional to the height $(\mathrm{H})$ of the dam are based on these well-founded previous studies.

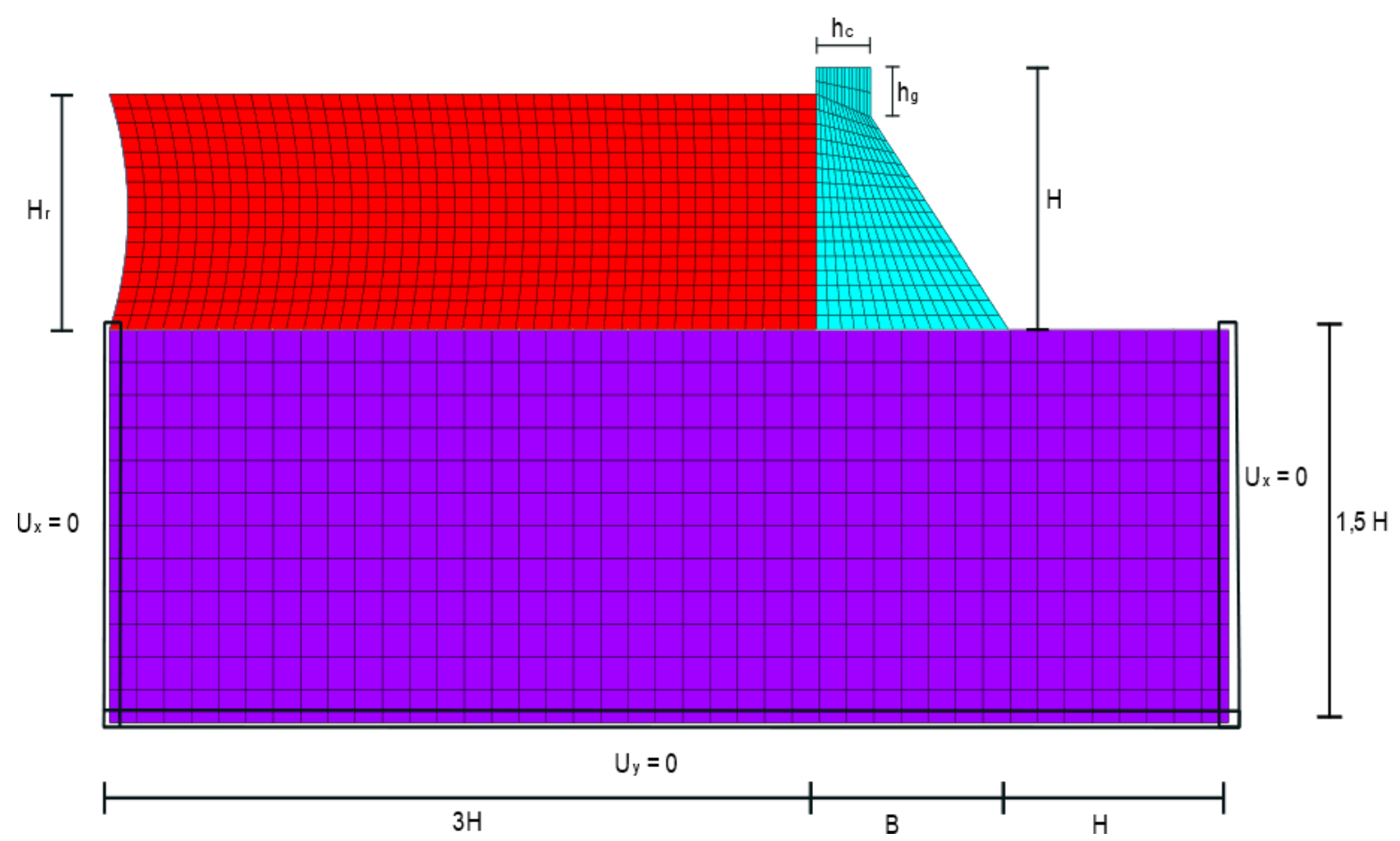

Figure 4. Modeling of the dam-reservoir-foundation system and its proper dimensions.

\subsection{Free vibration study}

\section{- Free vibrations: dam-foundation system (empty reservoir)}

In this case, the values of the natural frequencies and their modal deformations were determined as a function of the influence of the variation of the foundation stiffness, evaluating the magnitudes of the natural frequencies and the possible changes in the mode shape of the dam-foundation system.

The natural frequencies of the structure due the foundation flexibility is presented in Table 3 . These results show that a decrease in the magnitudes of the frequencies occurs with the increase of the foundation flexibility. 
Table 3 Alteration of the first 4 natural frequencies in Hertz for a variation between the elasticity modules of the foundation and the concrete.

\begin{tabular}{cccc}
\hline \multirow{2}{*}{ Mode } & & $E_{f} / E_{c}$ & \\
& & $\mathbf{2}$ & $\mathbf{5}$ \\
\cline { 2 - 4 } & $\mathbf{1}$ & 4,02 & 4,38 \\
\hline $\mathbf{2}$ & 3,57 & 9,48 & 10,64 \\
\hline $\mathbf{3}$ & 7,99 & 9,91 & 11,17 \\
\hline $\mathbf{4}$ & 8,79 & 17,51 & 19,25 \\
\hline
\end{tabular}

Based in these results, it can be inferred that this reduction in the natural frequencies can take the structure to a zone of lower frequency, where the seismic load is more effective (low-frequency seismic frequency components that can coincide with the first frequencies of these structures).

In addition to modifying the frequency magnitudes of the system, the flexibility of the foundation also changes the mode shapes of the structure. This fact is observed in Figures 5 and 6 which present, respectively, the mode shape for the cases with more rigid foundation $(\mathrm{Ef} / \mathrm{Ec}=5)$ and flexible $(\mathrm{Ef} / \mathrm{Ec}=1)$, signaling that a more significant change occurs in the second and third modes in both cases, where in the first and fourth modes, the deformed are analogous.

1st mode

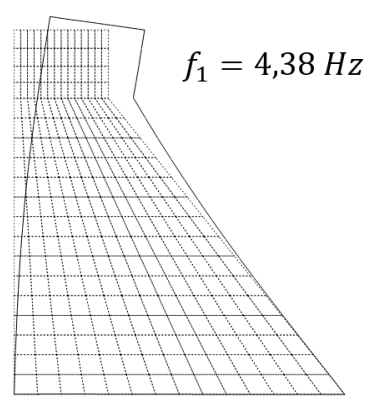

2nd mode

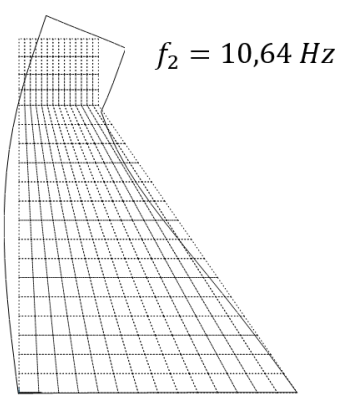

3rd mode

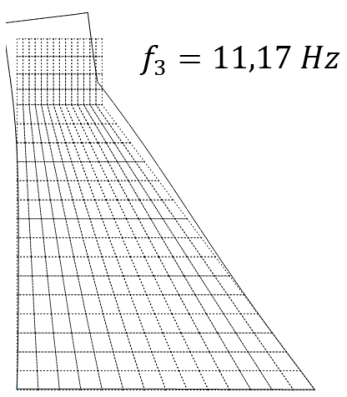

4th mode

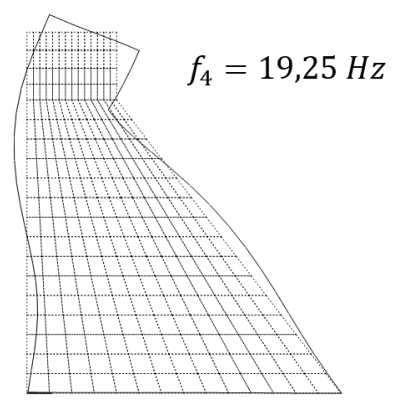

Figure 5. Vibration modes for the rigid foundation structure $\left(E_{f} / E_{c}=5\right)$.

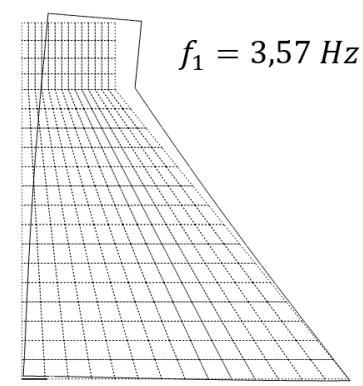

1st mode

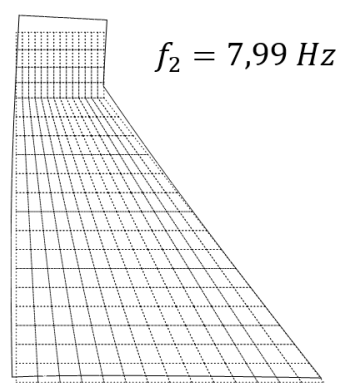

2nd mode

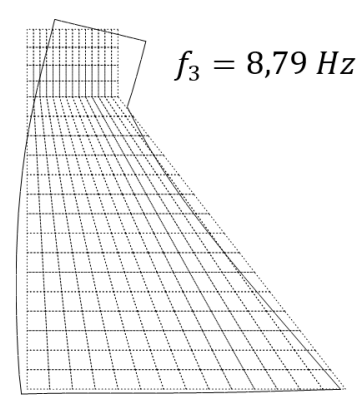

3rd mode

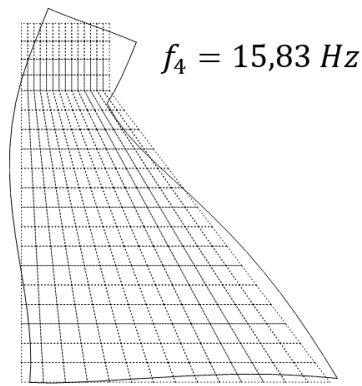

4th mode

Figure 6. Modes of vibration for the structure with flexible foundation $\left(\mathrm{E}_{\mathrm{f}} / \mathrm{E}_{\mathrm{c}}=1\right)$.

Therefore, the effect of the foundation flexibility not only decreases the natural frequencies, but also can change the mode shapes, as can be observed in the comparison between Figures 5 and 6, for the 2nd and 3rd modes.

- Free Vibration of the Decoupled Reservoir

In the study of free vibrations for the decoupled reservoir, the zero-pressure condition was considered in the distant contour and the results of the natural frequencies were compared with an analytical expression which represents a 
closed-open acoustic cavity in the $\mathrm{x}$ and $\mathrm{y}$ directions. The analytical solution is given by Equation 6 for $\mathrm{i}$ and $\mathrm{j}=1,2$, 3 ..., where $\mathrm{c}$ is the velocity of sound in the fluid, $\mathrm{L}$ is the length of the reservoir and $\mathrm{H}$ is the height of the fluid.

$$
f_{\text {anl. }}^{i, j}=\frac{1}{2 \pi} \sqrt{\left(\pi c^{2}\right)\left(\frac{(2 i-1)^{2}}{4 L^{2}}+\frac{(2 j-1)^{2}}{4 H^{2}}\right)}
$$

The Figure 7 shows the first four mode shapes for the decoupled reservoir and their respective natural numerical and analytical frequencies. It is observed that the results show insignificant errors between the frequencies.

\section{1st mode}

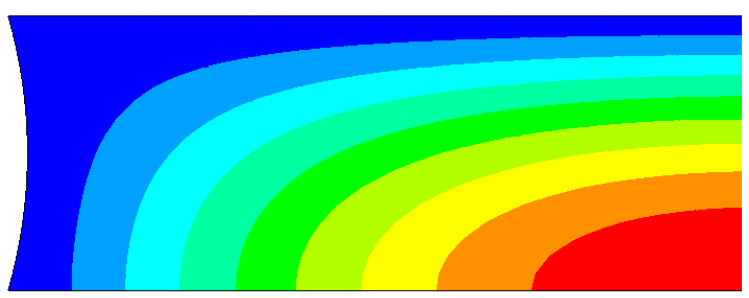

$$
f_{\text {num }}=5,20 \mathrm{~Hz} \quad f_{\text {anal. }}^{1,1}=5,22 \mathrm{~Hz}
$$

\section{3rd mode}

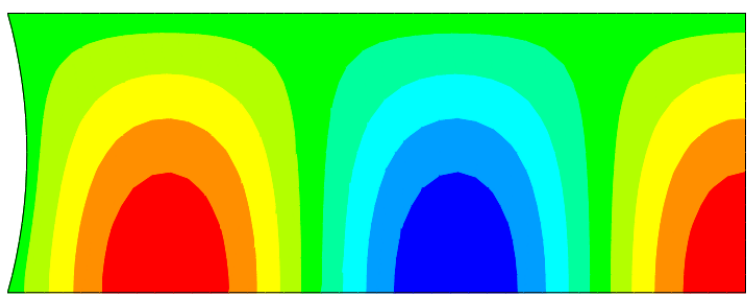

$$
f_{\text {num }}=8,95 \mathrm{~Hz}
$$

$f_{\text {anal. }}^{3,1}=9,01 \mathrm{~Hz}$ 2nd mode

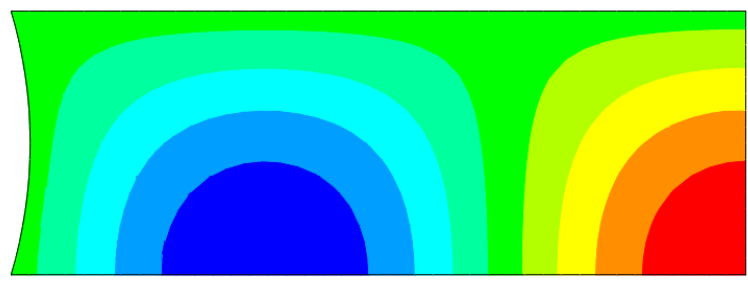

$f_{\text {num }}=6,69 \mathrm{~Hz}$

$$
f_{\text {anal. }}^{2,1}=6,72 \mathrm{~Hz}
$$

\section{4th mode}

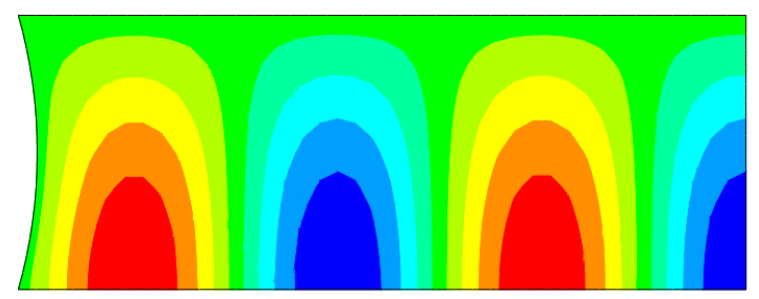

$$
f_{\text {num }}=11,52 \mathrm{~Hz} \quad f_{\text {anal. }}^{4,1}=11,63 \mathrm{~Hz}
$$

Figure 7. Vibration modes to the reservoir.

\begin{tabular}{|c|c|c|c|c|c|c|c|c|}
\hline \multirow[b]{3}{*}{ Mode } & \multicolumn{4}{|c|}{$E_{f} / E_{c}$} & & & \multicolumn{2}{|c|}{ Reservoir } \\
\hline & \multicolumn{2}{|c|}{1} & \multicolumn{2}{|c|}{2} & \multicolumn{2}{|c|}{5} & & \\
\hline & (DS) & (CS) & (DS) & (CS) & (DS) & (CS) & $\begin{array}{c}\text { Finite } \\
\text { element }\end{array}$ & Analytical \\
\hline 1 & 3,57 & 3,05 & 4,02 & 3,48 & 4,38 & $3,85^{*}$ & 5,20 & 5,22 \\
\hline 2 & 7,99 & 5,18 & 9,48 & 5,20 & 10,64 & 5,22 & 6,69 & 6,72 \\
\hline 3 & 8,79 & 5,98 & 9,91 & 6,03 & 11,17 & 6,05 & 8,95 & 9,01 \\
\hline 4 & 15,83 & 7,15 & 17,51 & 7,38 & 19,25 & 7,04 & 11,52 & 11,63 \\
\hline
\end{tabular}

- Free Vibration coupled: dam-reservoir-foundation system

Considering the dam-reservoir-foundation coupled system, it was observed a reduction in the frequencies with the inclusion of the reservoir in relation to the previous case, when comparing the results presented in Table 4.

Table 4 Results of the first 4 natural frequencies in Hertz of the decoupled system (DS) and coupled (CS) dam-reservoir

* additional mass mode 
However, these results also showed a more preponderant influence of the foundation flexibility on the natural frequencies of the coupled system for the 1st mode in comparison to the presence of the reservoir.

Analyzing the coupled problem - Figure 8 - it is observed that the first mode is of dominant structure and represents the mode of additional mass, in which the fluid is incompressible and follows the movement of the structure.

1st mode

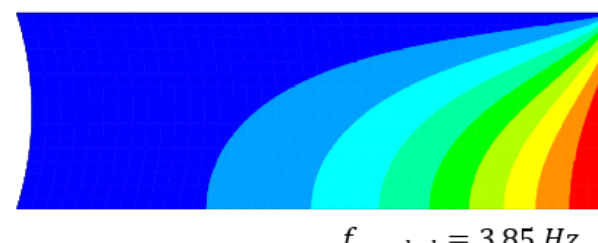

2nd mode

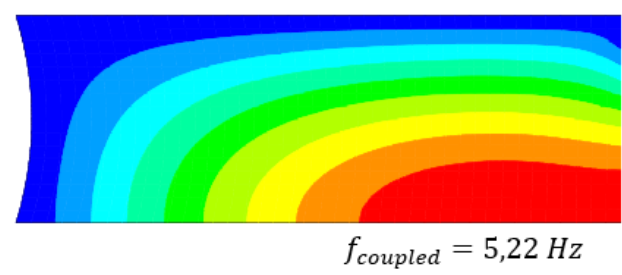

3rd mode

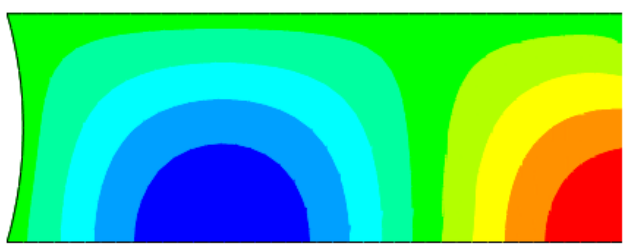

$f_{\text {coupled }}=6,05 \mathrm{~Hz}$

4th mode

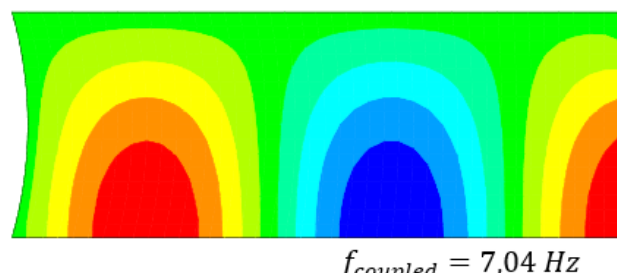

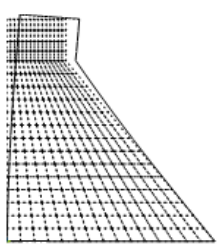
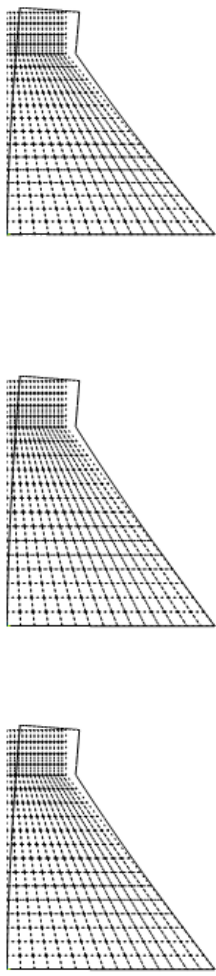

Figure 8. Vibration modes coupled in terms of pressure for the reservoir and displacements for the dam in the case of a rigid foundation.

However, the other modes $\left(2^{\circ}, 3^{\circ}\right.$ and $\left.4^{\circ}\right)$ are dominant in the reservoir and the mode shapes of the reservoir reproduce the same mode shapes of the decoupled case, but with slightly altered frequencies. The structure behaves practically as in a rigid wall, with a slightly flexible mode shape in its 1 st decoupled mode.

\section{- Seismic Excitation}

For the study of the influence of dam-reservoir-foundation interaction under a seismic excitation, the system's response in terms of maximum principal displacements and stresses was verified at some points of the dam. For this seismic analysis, the two cases already studied in free vibrations were evaluated: 1) dam-foundation; 2) dam-reservoirfoundation.

For the transient analysis, it was used a historical seismic record of acceleration compatible with a region of Brazil with a maximum magnitude of $0,10 \mathrm{~g}$; as shown in Figure 9. The frequency components of this accelerogram (frequency spectrum) are shown in Figure 10. 


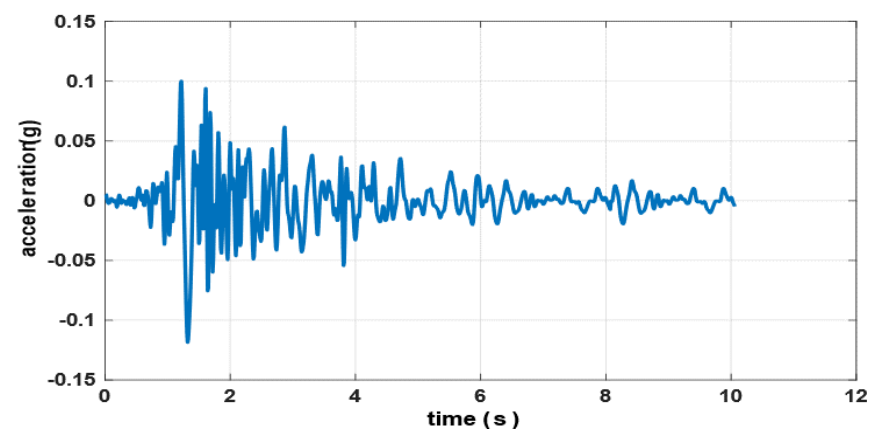

Figure 9. History of accelerations for a typical Brazilian earthquake under acceleration $\mathrm{g}$.

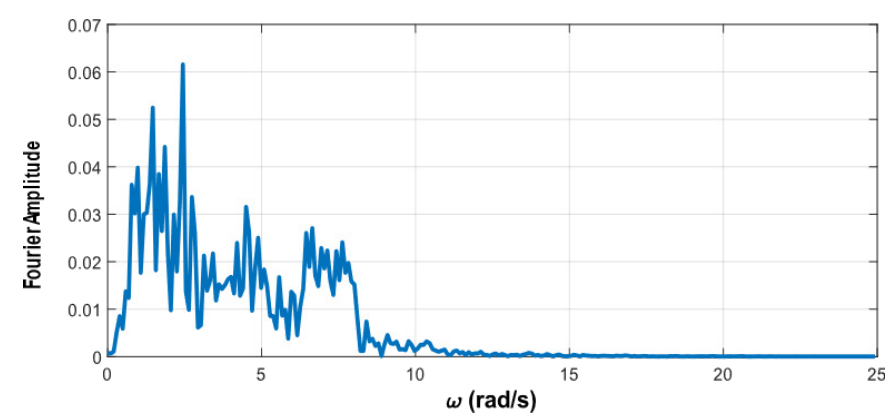

Figure 10. Spectral analysis of the Brazilian earthquake.

According to the proposal for the new seismic threat map in Brazil, shown in Figure 11, which improves the data of the anti-seismic standard (NBR-15421/2006), the earthquake assessed in this work has a probability of $2 \%$ probability to occur in most of Brazil for a period of 50 years.

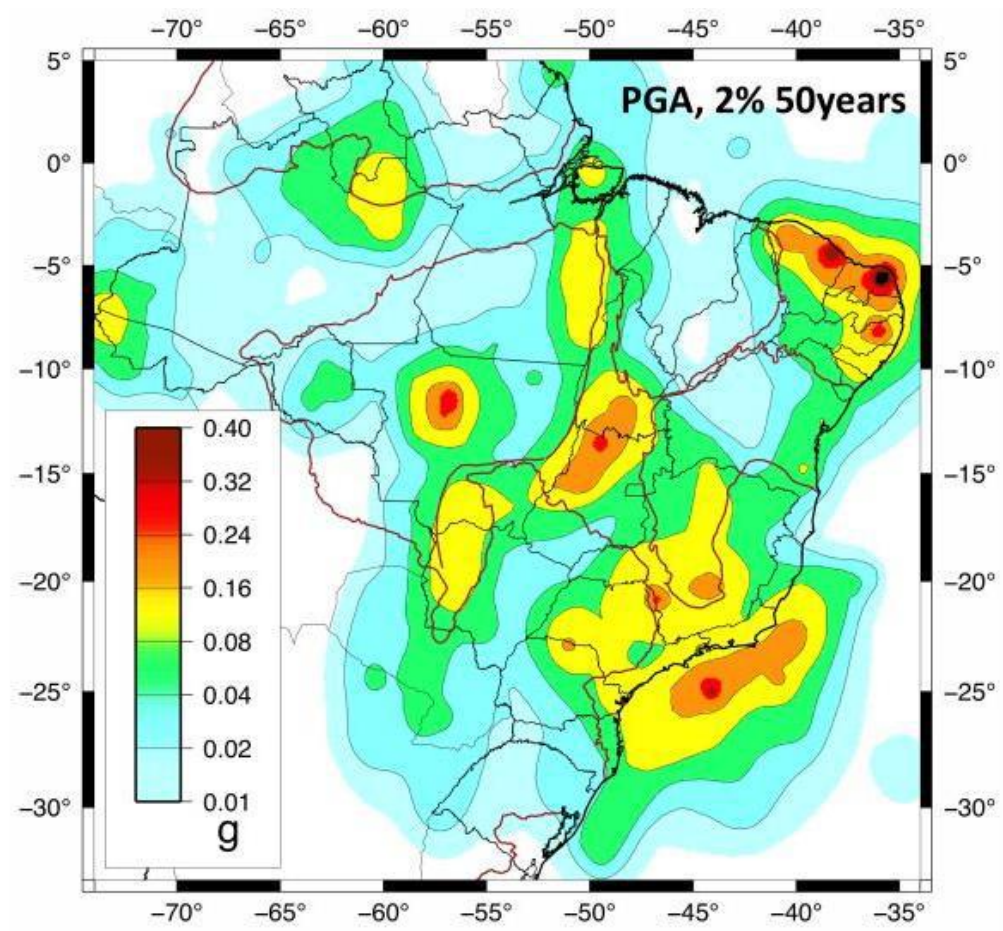

Figure 11. Brazilian seismic threat map in acceleration units g. (Disclosure/Prof.Dr. Marcelo S. Assumpção). 
The inclusion of the earthquake in the cases studied is performed by the application of acceleration at the base of the structure (region of contact between the dam and the foundation).

In this analysis of seismic excitation, the structure response was studied in terms of maximum crest displacements and maximum stresses at three singular points of the dam: heel, finger and bottleneck (transition region), evaluating the influences of the foundation and of the reservoir. These points of analysis, whose denominations can be assimilated the parts of a human limb (foot), are best presented in Figure 12.

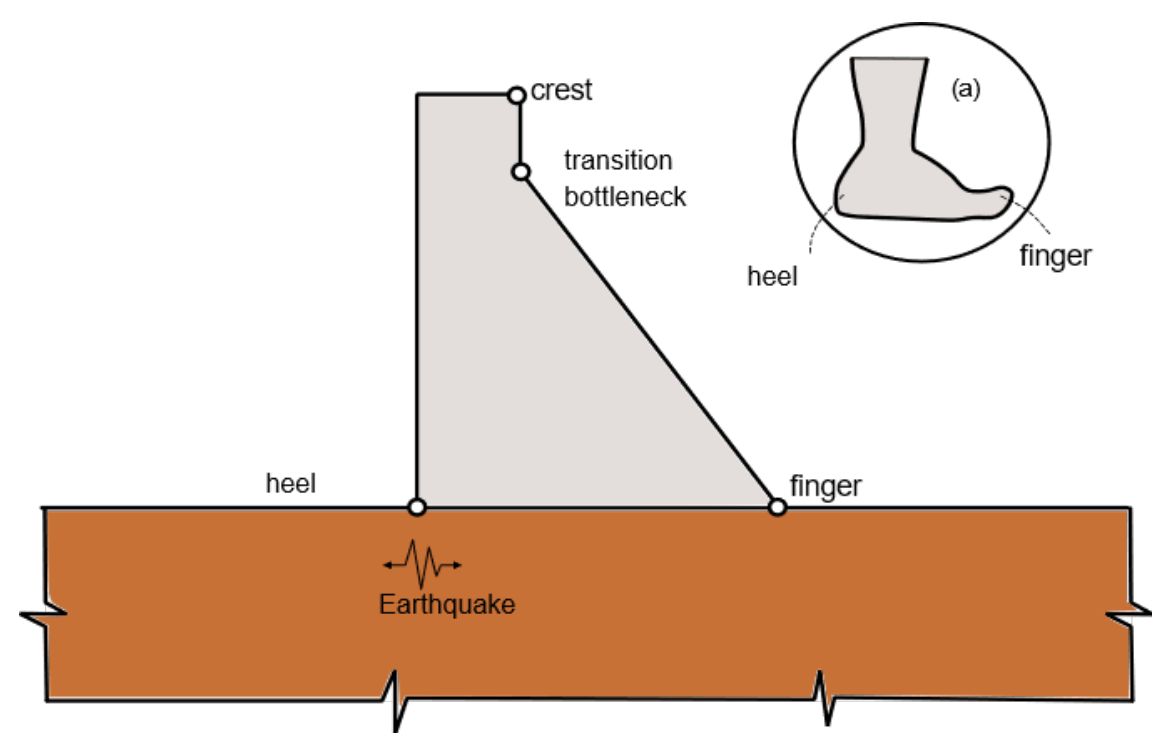

Figure 12. Points to be analyzed in the profile of the dam under seismic excitation.

1) Coupled system Dam-Foundation

For the dam-foundation system case, it was initially evaluated the displacement at the crest of the dam, shown in Figure 13, which shows a comparison between the maximum horizontal displacements (ordinate axis) versus the variation of the modulus of elasticity between foundation and concrete (abscissa axis). It can be observed that the maximum magnitudes close to $10 \mathrm{~mm}$. Moreover, it is noted that the maximum displacements at the crest of the dam have decreased as the modulus of elasticity of the foundation increases.

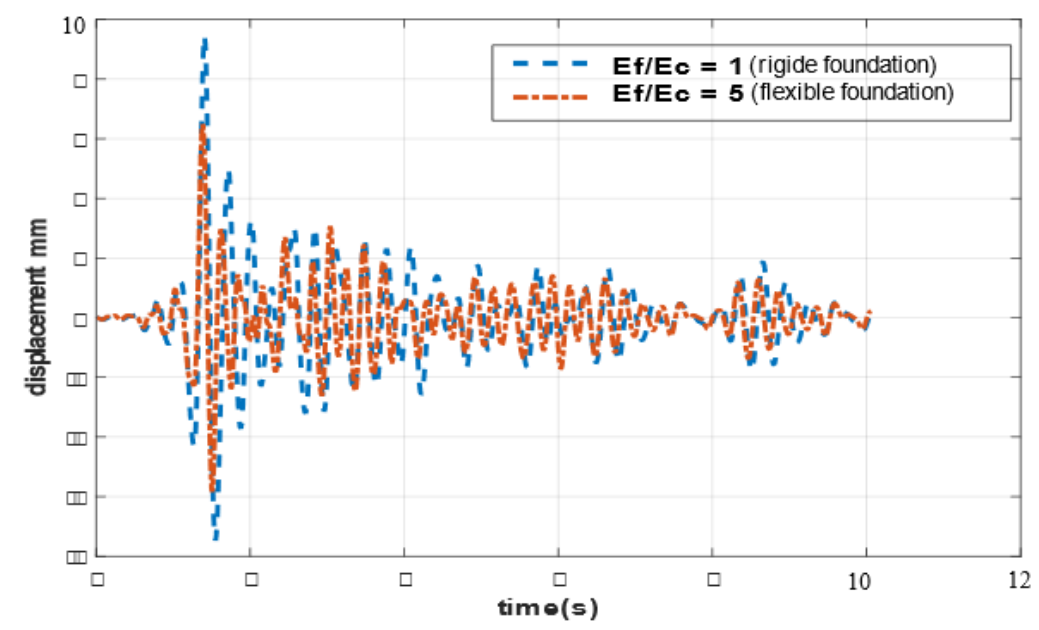

Figure 13. Variation in time of displacements on the crest of the dam as a function of the effect of the foundation. 
The results obtained for the maximum principal stresses in the heel of the dam are shown in Figure 12, a region where the stresses normally reach its largest magnitudes. Figure 14 shows the change in the stresses with the change in the flexibility of the foundation, in which again it is observed that the increase of the modulus of elasticity of the foundation causes a substantial decrease in the effect of the seismic load in terms of tensile stresses.

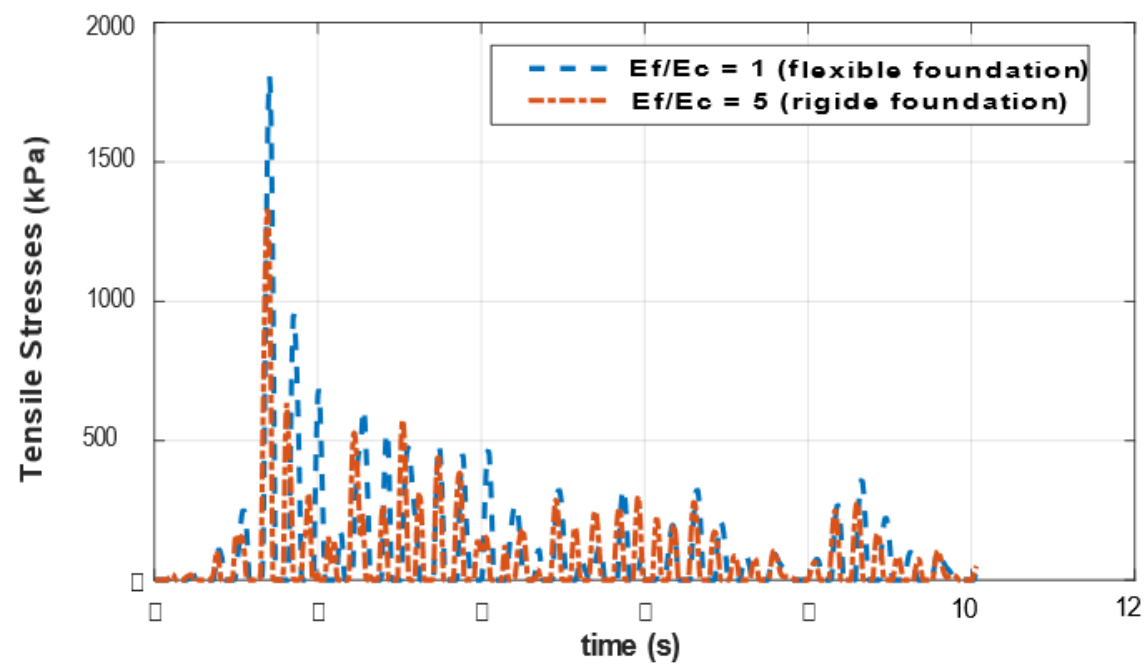

Figure 14. Variation in time of the maximum main stresses in the dam's heel according to the effect of the foundation.

When evaluating the history of maximum stresses in the three singular points: heel, bottleneck, and finger of the dam as a function of the flexibility of the foundation, it can be seen that it is in the region of the heel of the dam that the greatest stresses are found, followed by the bottleneck and the foot of the dam, respectively, as it can be verified in Figure 15. However, as the elasticity of the foundation increases, an increase in stresses occurs in the superior region of the structure (bottleneck), differently from what occurs in the heel and toe of the dam, where there is a tendency for reduction.

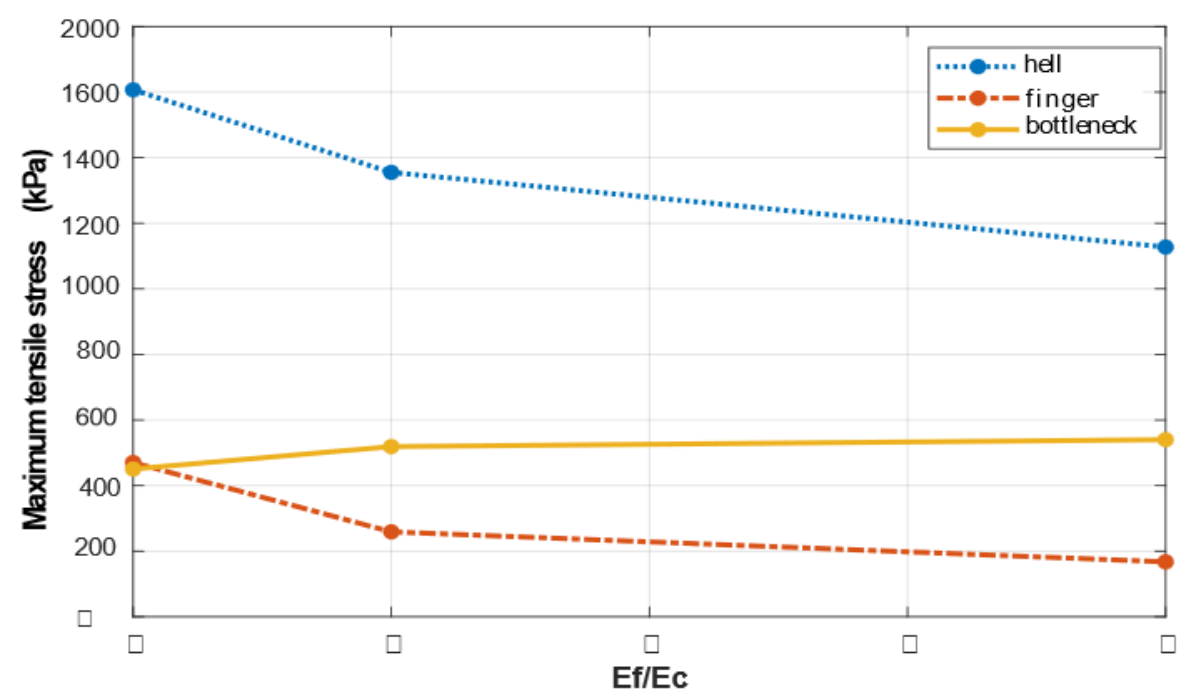

Figure 15. Variation of the maximum principal stresses in the heel, finger, and bottleneck of the dam according to the effect of the foundation. 


\section{2) Coupled system Dam-Foundation-Reservoir}

For the evaluation of the effect of the presence of the reservoir in the coupled system, it was proposed a study similar to the one done in the previous item, in which the displacements and the maximum stresses in some singular points of the structure were evaluated. However, it was also considered in this step the verification of the influence of the distant boundary condition of the reservoir (zero pressure condition and the Sommerfield condition representing the wave absorption).

For the purpose of design, the zero-pressure condition is the simplest to be added, unlike the non-return condition of the wave, which has its peculiarities as a function of the analysis program. Thus, this study aims to verify the difference that exists in the results when considering these two different cases.

Figure 16 shows the results for the displacement at the crest of the dam considering these two cases and adopting the rigid foundation condition. It is observed from the figure that the displacements were equivalent both by the evaluation of the zero-pressure condition and the non-return condition (Sommerfield condition), with no significant differences in the results. The observed effects cannot be generalized, because the conditions of the presented case were favorable to this similarity in the results. However, with the change of certain conditions, to be seen in the next case, there is already a differentiation in the results.

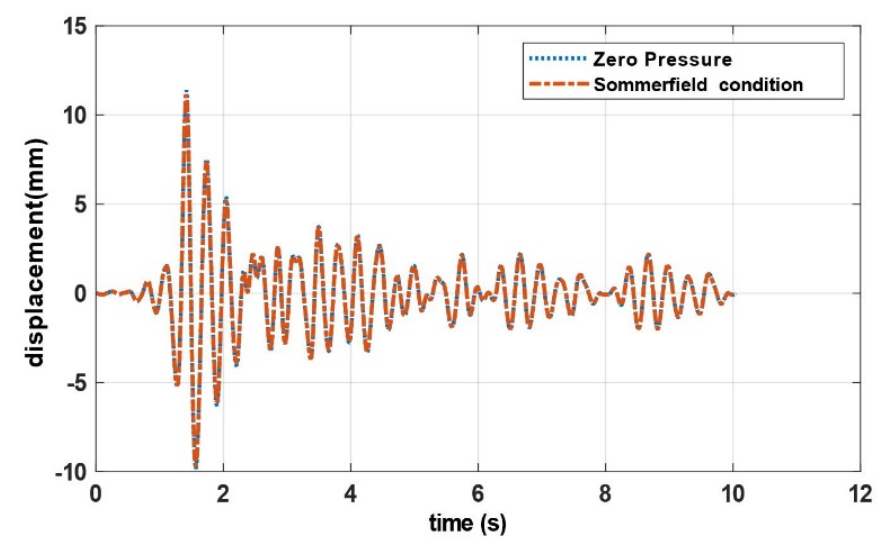

Figure 16. Variation in time of the displacement of the crest of the dam with the change of the boundary distant condition of the reservoir for a rigid foundation.

When assessing the influence of the foundation on the displacements at the dam crest for the cases in which is considered the rigid foundation $(\mathrm{Ef} / \mathrm{Ec}=1)$ and rigid $(\mathrm{Ef} / \mathrm{Ec}=5)$, shown in Figure 17, it was observed that the flexible foundation condition caused an increase in the magnitudes of the displacements. When comparing the results of the analysis in which only the dam-foundation interaction is considered (see Figure 13), there is an increase in the displacements with the inclusion of the reservoir effect.

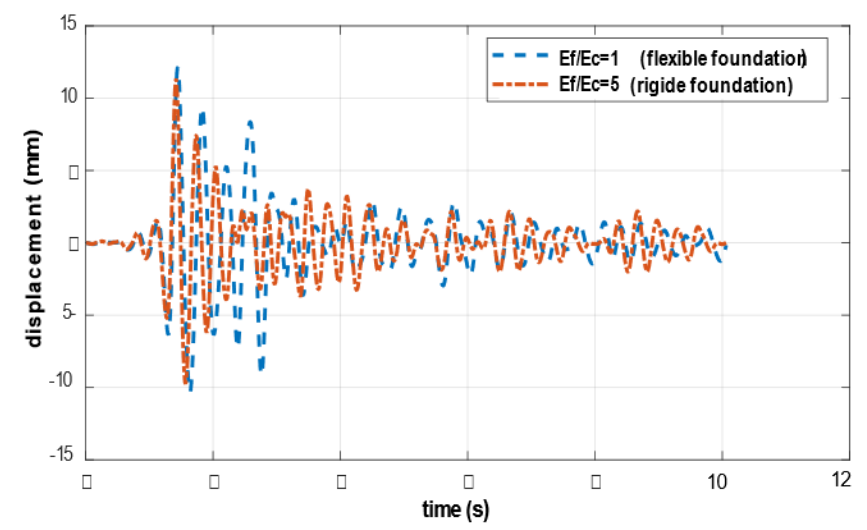

Figure 17. Variation in time of the displacement of the crest of the dam according to the effect of the foundation. 
Similarly, for the heel stresses of the dam, an increase in the magnitudes of the maximum principal stresses was observed with the inclusion of the reservoir (Figure 18). This increase can cause problems in the structure since the tensile stresses that occur in the concrete approaching $2000 \mathrm{kPa}$ tend to cause damage to the dam. It is also observed that in this case the flexibility of the foundation did not produce a result as significant as that seen in the item in which it was considered the dam-foundation system (see Figure 14).

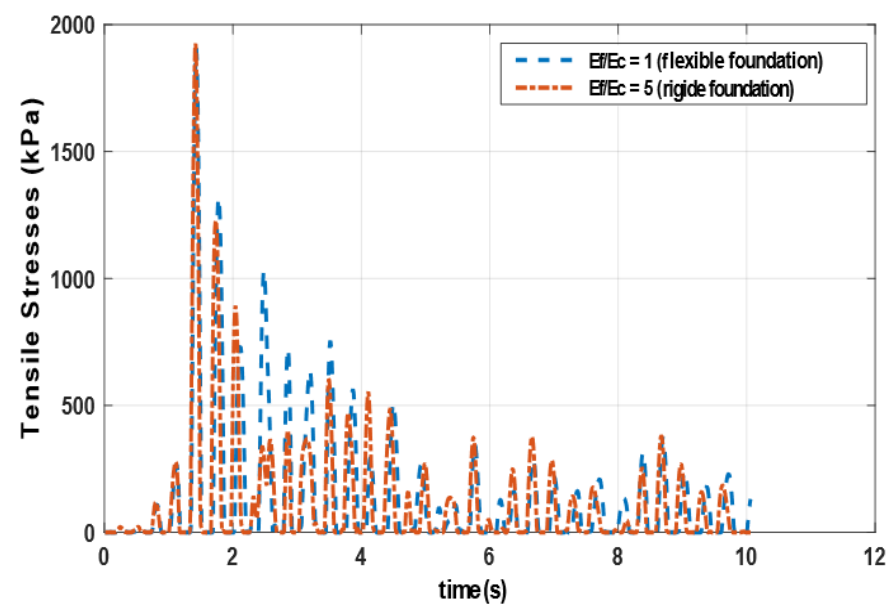

Figure 18. Variation of maximum stresses at the dam's heel.

The variation of the maximum tensile stresses was also evaluated in the other singular points of the structure, where the influence of the foundation was verified. It is observed in Figure 19 that the inclusion of the reservoir caused an increase in the level in the stresses in relation to the case without the reservoir (see Figure 15), as well as a decrease of these with the increase of the elasticity of the foundation to the heel and the finger of the structure.

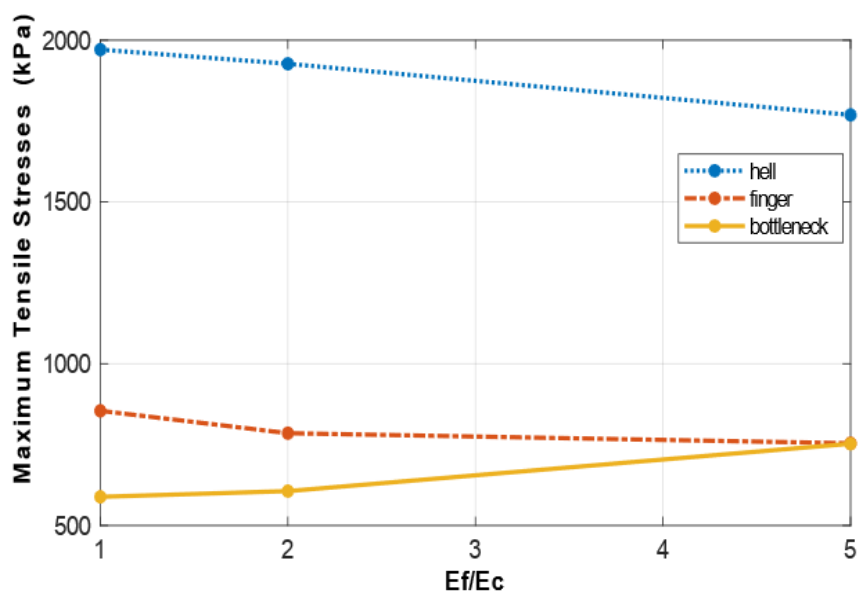

Figure 19. Variation of maximum stresses in the heel, finger, and bottleneck of the dam according to the effect of the foundation.

However, the bottleneck region was less susceptible to the presence of the reservoir, for the higher ratios Ef/Ec (rigid foundation). For the more flexible foundation there was even a slight decrease of stresses with the presence of reservoir, characterizing a behavior different from the standard of the other points analyzed.

It should be noted that the flexibility of the foundation altered the magnitudes of the stresses, especially in the interval in which the earthquake had its greatest intensity, see interval of 1 to $2 \mathrm{~s}$ in Figure 9. 
The seismic load causes a "come and go" movement in the structure and this causes the effects of stresses in different regions of the dam body to be different along the soil movement. This becomes clear when one observes Figure 20, which presents the mapping of the stresses at the dam for the instant of the maximum upstream and downstream forces for the case of the filled reservoir and rigid foundation $(\mathrm{Ef} / \mathrm{Ec}=5)$.

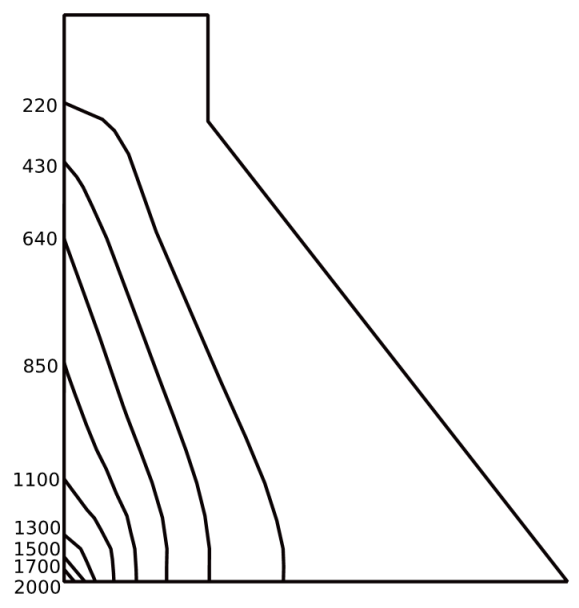

(a)

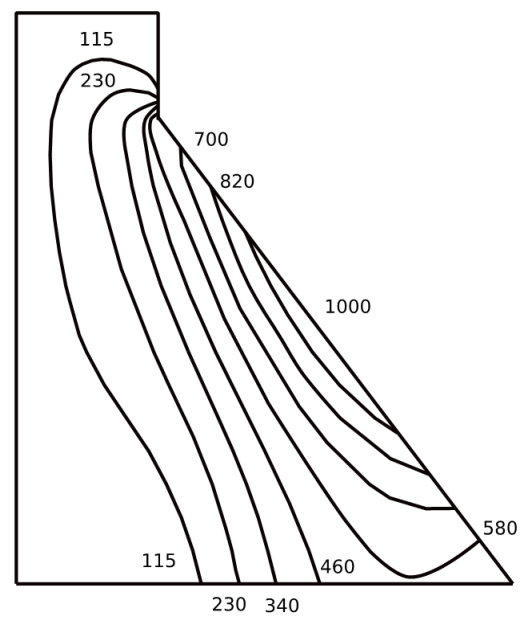

(b)

Figure 20. Time for maximum stresses of tensile in the dam body: (a) upstream $t=1,39 \mathrm{~s}$ and (b) downstream $t=1,50 \mathrm{~s}$.

The heel region shows the highest stress concentrations as well as the structure bottleneck. And these effects can be amplified, as emphasized in this study, by changes in the elasticity of the foundation.

It is observed that the stresses along the heel region are much greater than those with respect to other points of the structure. At $\mathrm{t}=1,39 \mathrm{~s}$, a stress around $2000 \mathrm{kPa}$ was obtained in this region, while at $\mathrm{t}=1,50 \mathrm{~s}$ values of $1000 \mathrm{kPa}$ occur in the intermediate region between the bottleneck and the finger on the downstream side of the dam. Thus, it is evident that the maximum stresses in the dam for a seismic excitation do not happen at the same instant, that is, there are intervals of time in which the upstream region is the most loaded, while in other time intervals the downstream of the structure is the most loaded region.

\section{CONCLUSIONS}

This work presented a dynamic study of the behavior of the dam - reservoir - foundation interaction in terms of free vibrations and under seismic load. For this, finite element models were developed through the ANSYS program in the APDL language. After the different simulations presented in this paper, some important conclusions were reached, namely:

- In the study of free vibrations, two systems were evaluated: 1) dam-foundation (BF) - empty reservoir; 2) damfoundation-reservoir (BFR). For both cases, the influence of the foundation was observed, and it was verified that a reduction in the natural frequencies occurs for the more flexible foundations, fact that, in turn, also causes changes in the mode shape of the dam. In the case of the three coupled media, it was observed that the first mode is controlled by the dam (additional mass), and with the decrease of the stiffness of the foundation the reduction of this first natural frequency occurs more significantly, unlike the other higher modes which are controlled by the reservoir and in which this variation is not so striking in the magnitudes of the frequencies with the variation in the stiffness of the foundation.

- In the seismic analysis the displacements and the maximum stresses in some singular points of the dam were verified for a given acceleration history with a maximum intensity of $0.10 \mathrm{~g}$. In the seismic analysis, also, a similar influence was observed in the previous item due to the influences of the foundation and the reservoir. For the crest displacements, and the stresses at the heel and foot of the dam, a reduction was observed with the increase of the stiffness of the foundation; on the contrary, an increase in the maximum stress variation was observed in the bottleneck. 
- Another highlight corresponds to a comparison of the distant boundary conditions in the reservoir: the zero-pressure and the Sommerfield condition for rigid foundation. When considering both cases the results were similar, thus assuring us that the simpler condition (zero pressure) similarly reproduces the results for a rigid foundation seismic analysis.

- Finally, the authors recommend that in a dynamic analysis of dams, all the parameters involved should be analyzed in a way that is consistent with the conditions present in the dam-reservoir-foundation system, especially in the properties that influence the elasticity of the foundation. Regarding the reservoir, the simplified models of additional mass and zero pressure in the distant contours can be considered, in preliminary stages of design.

\section{ACKNOWLEDGEMENTS}

The authors thank the National Committee of Scientific and Technological Development (CNPq) and the University of Brasília (UnB), through the PECC.

\section{REFERENCES}

[1] A. Løkke and A. K. Chopra, "Direct finite element method for nonlinear earthquake analysis of 3-dimensional semi-unbounded damwater-foundation rock systems," Earthquake Eng. Struct. Dynam., vol. 47, no. 5, pp. 1309-1328, Apr 2018, http://dx.doi.org/10.1002/eqe.3019.

[2] N. B. Mendes, "Um estudo de propagação de ondas e lançamento do sismo na análise dinâmica acoplada barragem em arco reservatório - fundação," Ph.D. dissertation, Univ. Brasilia, Brasília, 2018.

[3] H. M. Westergaard, "Water pressures on dams during earthquakes," Trans. ASCE, vol. 95, pp. 418-433, 1933. Accessed: Dec. 16, 2019. [Online]. Available: http://ci.nii.ac.jp/naid/10002935681/en/

[4] A. K. Chopra, "Earthquake resistant design of concrete gravity dams," J. Struct. Div., vol. 104, no. 6, pp. 953-971, 1978.

[5] A. K. Chopra and P. Chakrabarti, "Earthquake analysis of concrete gravity dams including dam-water-foundation rock interaction," Earthquake Eng. Struct. Dynam., vol. 9, no. 4, pp. 363-383, 1981, http://dx.doi.org/10.1002/eqe.4290090406.

[6] J. F. Hall and A. K. Chopra, "Hydrodynamic effects in the dynamic response of concrete gravity dams," Earthquake Eng. Struct. Dynam., vol. 10, no. 2, pp. 333-345, Mar 1982, http://dx.doi.org/10.1002/eqe.4290100212.

[7] G. Fenves and A. K. Chopra, Earthquake Analysis and Response of Concrete Gravity Dams, 1st ed. Califórnia: Univ. California, 1984.

[8] A. K. Chopra and L. Zhang, "Earthquake-induced base sliding of concrete gravity dams," J. Struct. Eng., vol. 117, no. 12, pp. 36983719, Dec 1991, http://dx.doi.org/10.1061/(ASCE)0733-9445(1991)117:12(3698).

[9] P. M. V. Ribeiro and L. J. Pedroso, "Dynamic response of dam-reservoir systems: review and a semi-analytical proposal," Lat. Am. J. Solids Struct., vol. 14, no. 4, pp. 594-612, Mar 2017, http://dx.doi.org/10.1590/1679-78253500.

[10] M. Novak, "Dynamic soil-structure interaction, John P. Wolf, Prentice-Hall, Englewood Cliffs, N.J., 1985. No. of pages: £466. Price: £61.45," Earthquake Eng. Struct. Dynam., vol. 14, no. 6, pp. 951, Nov 1986., http://dx.doi.org/10.1002/eqe.4290140610.

$<$ jrn>[11] P. Léger and M. Katsouli, "Seismic stability of concrete gravity dams," Earthquake Eng. Struct. Dynam., vol. 18, no. 6, pp. 889-902, Aug 1989, http://dx.doi.org/10.1002/eqe.4290180611.</jrn>

[12] S. Bougacha, J. L. Tassoulas, and J. M. Roësset, "Analysis of foundations on fluid-filled poroelastic stratum," J. Eng. Mech., vol. 119, no. 8, pp. 1632-1648, Aug 1993, http://dx.doi.org/10.1061/(ASCE)0733-9399(1993)119:8(1632).

[13] Y. Ghanaat, "Failure modes approach to safety evaluation of dams," in Proc. 13th World Conf. Earthq. Eng., Vancouver, 2004.

$<\mathrm{jrn}>[14]$ J. A. Inaudi, E. E. Matheu, R. L. Poeppelman, and A. Matusevich, Foundation Flexibility Effects on the Seismic Response of Concrete Gravity Dams. Tech. Memo. Public Works Res. Inst., 2005, pp. 269-289.</jrn>

[15] G. Lin, J. Du, and Z. Hu, "Earthquake analysis of arch and gravity dams including the effects of foundation inhomogeneity," Front. Archit. Civ. Eng. China, vol. 1, no. 1, pp. 41-50, Feb 2007, http://dx.doi.org/10.1007/s11709-007-0004-4.

[16] G. Papazafeiropoulos, Y. Tsompanakis, and P. N. Psarropoulos, "Dynamic interaction of concrete dam-reservoir-foundation: analytical and numerical solutions," in Computational Methods in Earthquake Engineering, M. Papadrakakis, M. Fragiadakis, N. D. Lagaros, Ed., Switzerland: Springer, 2011, pp. 455-488.

[17] A. Burman, P. Nayak, P. Agrawal, and D. Maity, "Coupled gravity dam-foundation analysis using a simplified direct method of soilstructure interaction," Soil. Dyn. Earthquake Eng., vol. 34, no. 1, pp. 62-68, 2012, http://dx.doi.org/10.1016/j.soildyn.2011.10.008.

[18] A. K. Chopra, "Earthquake analysis of concrete dams: factors to be considered," in Tenth U.S. Nat. Conf. Earthq. Eng., Anchorage, Alaska, 2014.

[19] L. J. Pedroso, Fundamentos Teóricos-Numéricos para a Compreensão do Problema Acoplado Barragem-Reservatório-Fundação com Contornos Absorventes Longínquos, Superficie Livre, e Interação entre os Três Meios pelo Método das Diferenças Finitas. Brasília, 2017. 
[20] L. J. Pedroso, "Interação fluido-estrutura," in Notas de Curso e Apostila Didática. Brasilia: Prog. Pós-grad. Estrut. Constr. Civ., 1992.

[21] L. J. Pedroso, "Formulações potencias para abordagens fluido-estrutura," in Notas do Curso de Interação Fluido-Estrutura e Apostila Didática. Brasilia: Prog. Pós-grad. Estrut. Constr. Civ., 2004.

[22] I. V. Silveira and L. J. Pedroso, "Analysis of natural frequencies and modes of vibration involving interaction dam-reservoirfoundation for concrete gravity dams," in Third Int. Dam World Conf., 2018, p. 11.

[23] B. A. Zeidan, "Seismic analysis of dam-reservoir-foundation interaction for concrete gravity dams," in ICOLD2013, 2014, Vience, Italy.

[24] J. Huang, "Seismic response evaluation of concrete gravity dams subjected to spatially varying earthquake ground motions," Ph.D. dissertation, Drexel Univ., Drexel, 2011.

[25] C. A. Nascimento Jr., "Um estudo comparativo analítico-numérico de tensões locais e globais em barragens gravidade de concreto," M.S. thesis, Univ. Brasília, Brasília, 2016.

[26] D. Gutstein, "Estudo das tensões em fundações de barragens de gravidade de concreto por meio do método dos elementos finitos," M.S. thesis, Univ. Santa Catarina, Florianópolis, 2003.

Author contributions: IVS: methodology, numerical modelling, investigation, formal analysis, writing - original draft; LJP and GSM: supervision, conceptualization, review, editing.

Editors: Bernardo Horowitz, José Luiz Antunes de Oliveira e Sousa, Guilherme Aris Parsekian. 